\title{
INOVASI JAKET BATIK MENJADI LEBIH AMAN DAN NYAMAN
}

\author{
Garin Priambodo \\ Program Studi Ekonomi Pembangunan \\ Universitas Pembangunan Nasional "Veteran" Yogyakarta \\ e-mail : garinpriambodo@gmail.com. \\ Firgo Saputra \\ Program Studi Ekonomi Pembangunan \\ Universitas Pembangunan Nasional "Veteran" Yogyakarta \\ e-mail : firgosaputra16@yahoo.com \\ Yoga Septrian \\ Program Studi Ekonomi Pembangunan \\ Universitas Pembangunan Nasional "Veteran" Yogyakarta \\ e-mail : yoga.septrian1@gmail.com \\ Salsabila Piriyanti Anam \\ Program Studi Ekonomi Pembangunan \\ Universitas Pembangunan Nasional "Veteran" Yogyakarta \\ e-mail :, salsabila.piriyanti@gmail.com
}

\begin{abstract}
Jatik Man is a creative and inovative product in expanding the Batik bussines opportunity (indonesia tradisional clothing) And combine with Jacket. Jatik Man : Jaket Batik Aman dan Nyaman, using soft and comfortable materials, added with flexible wind pillow, earphone that able to connected to our smartphone And also powerbank that available to use and equipped inside the jacket. Preparation, Promotion Strategy and Production is ongoing to do. Social media is focus of promotion strategy like Instagram. Based on target indicator, owner contribution has reached $83 \%$, until now, we are still developing our product until produce a perfect product. Our next plan is we will collaborate with Gift shop based in Yogyakarta, cause of so many tourist visit jogyakrta and also sales tren is growing up.
\end{abstract}

\begin{abstract}
ABSTRAK
Jatik Man, merupakan karya kreatif inovatif dalam memperluas peluang bisnis industri batik yang dipadukan dengan jaket. Jatik Man : Jaket Batik Aman dan Nyaman, menggunakan bahan yang lembut serta nyaman serta di lengkapi dengan bantal leher tiup yang fleksibel, ditambah dengan earphone yang menempel di telinga juga kabel yang dapat dicolokkan langsung di handphone yang sedang digunakan, dan tambahan powerbank yang dapat di gunakan oleh pengguna jaket itu sendiri. Tahapan kegiatan yang akan dilaksanakan meliputi persiapan, survey pasar, proses produksi. Dalam melakukan promosi dilakukan beberapa strategi promosi yaitu dengan media sosial (instagram). Berdasarkan indikator target luaran sudah tercapai sebesar $83 \%$, hingga saat ini kami masih terus melakukan pengembangan produk hingga tercapai bentuk sempurna dari produk yang kami tujukan. Rencana tahap berikutnya, melihat animo wisatawan yang berkunjung ke Yogyakarta dan trend penjualan yang sedang beranjak naik. Kami akan bekerja sama dengan pusat oleh-oleh yang berada di Yogyakarta.
\end{abstract}




\section{Buletin Ekonomi}

Kata Kunci : Jatik Man, jaket, batik, promosi, target

\section{PENDAHULUAN}

Batik adalah salah satu kesenian tradisional kebanggan Indonesia. Berdasarkan definisi dari Menteri Tenaga Kerja melalui Standar Kompetensi Kerja Nasional Indonesia (SKKNI) Nomor 314 Tahun 2013, batik adalah tekstil Indonesia yang motifnya dibuat dengan teknik pencelupan rintang. Pada 2 Oktober 2009, batik Indonesia diakui oleh United Nations Educational, Scientific and Cultural Organization (UNESCO) sebagai warian dunia (world heritage) non kebendaan.

Pengakuan internasional tersebut membuat batik menjadi salah satu sovenir khas Indonesia sehingga menjadi produk andalan yang ditawarkan kepada wisatawan domestik maupun asing. Hal ini membuat permintaan batik di pasaran meningkat, permintaan batik meningkat sebesar 30\% setiap bulannya dan permintaan batik menyebabkan produksinya juga meningkat. Nilai ekspor batik pada tahun 2017 senilai $\$ 58,46$ juta. Walaupun ekspor batik meningkat minat kaum muda untuk mengenakan batik masih rendah karena model dan kenyamanan dalam memakai batik masih kurang dalam segi estetika.

Di Yogyakarta sendiri merupakan tempat tujuan wisatawan baik asing maupun dalam negeri. Di lansir dari Dinas kepariwisataan Yogyakarta pada 5 tahun terakhir jumlah wisatawan mengalami peningkatan. Ini merupakan pangsa pasar yang besar bagi produk kami, mengingat bahwa jogja sangat khas dengan budayanya terutama batik. Terlebih lagi bahwa produk kami belum ada di pasaran Yogyakarta, hal tersebut membuat kami akan di minati oleh para wisatawan yang datang ke jogja baik itu golongan tua maupun muda karena desain yang kami tawarkan sangat cocok untuk di gunakan di segala umur.

Karena itu kami menginovasikan jaket yang aman dan fashionable agar kaum muda minat dan bangga menggunakan batik sebagai kearifan lokal. "Jatik man" ini menggunakan bahan yang lembut serta nyaman digunakan dalam segala kondisi serta di lengkapi dengan bantal leher tiup yang fleksibel, ditambah dengan earphone yang menempel di telinga juga kabel yang dapat dicolokkan langsung di handphone yang sedang digunakan, oleh pengguna jaket itu sendiri.

"Jatik Man" ini merupakan sebuah trobosan baru untuk mengangkat kearifan lokal yang fashionable, aman serta nyaman untuk digunakan dalam beraktivitas. Di Yogyakarta sendiri produsen "Jatik Man" masih belum ada sehingga pangsa pasar yang tersedia masih sangat luas untuk daerah Yogyakarta, apalagi Yogyakarta merupakan pusat industri batik sehingga bisa menjadi oleh-oleh khas Yogyakarta. 


\section{Buletin Ekonomi}

\section{METODE}

Pelaksanaan kegiatan PKM-K "JATIK-MAN" dilakukan dengan tahapan produksi yang pertama yaitu mendesain jaket. Berikut design "JATIK-MAN".

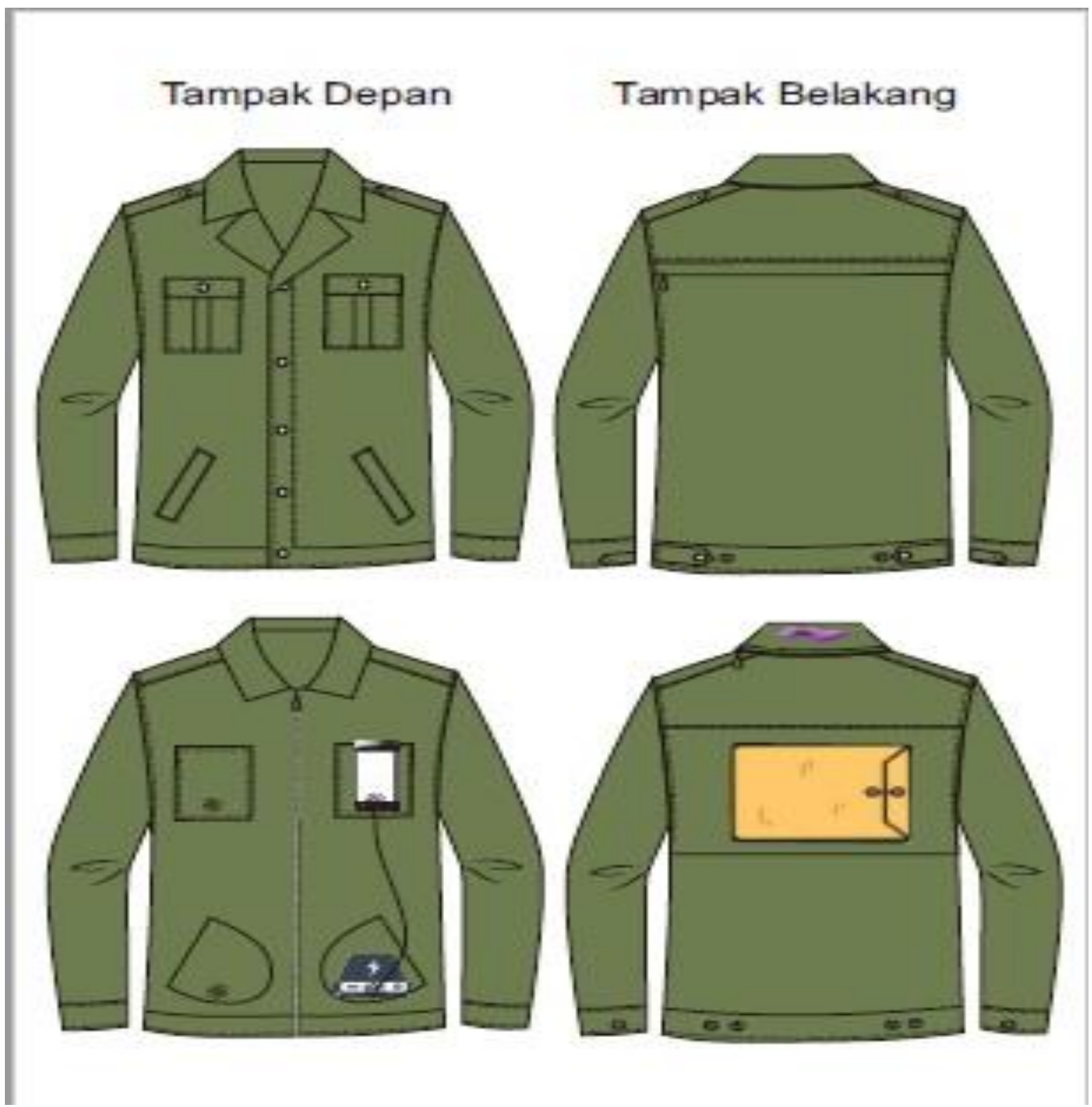

\section{Tahap Produksi}

Dibulan ke 1 kami melakukan survei bahan baku terutama kain dan konveksi. Untuk kain akhirnya kita pilih kain kanvas karena model "JATIK MAN" ini lebih mengarah ke model jaket roughneck yang dominan terbuat dari kain kanvas.. 


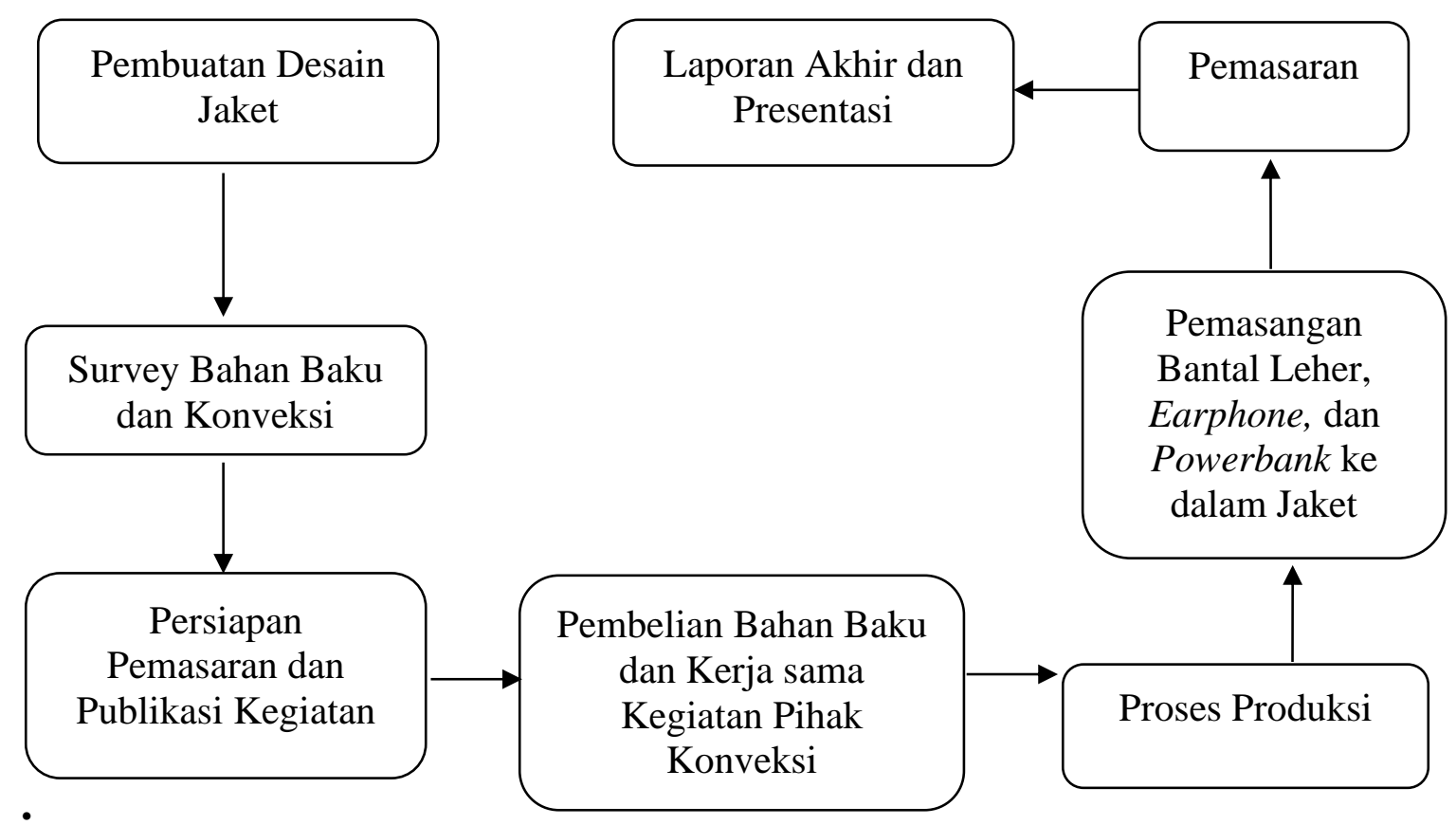

Berikut hasil dan model dari kegiatan ini, berupa "JATIK-MAN" saat digunakan sebagai berikut:
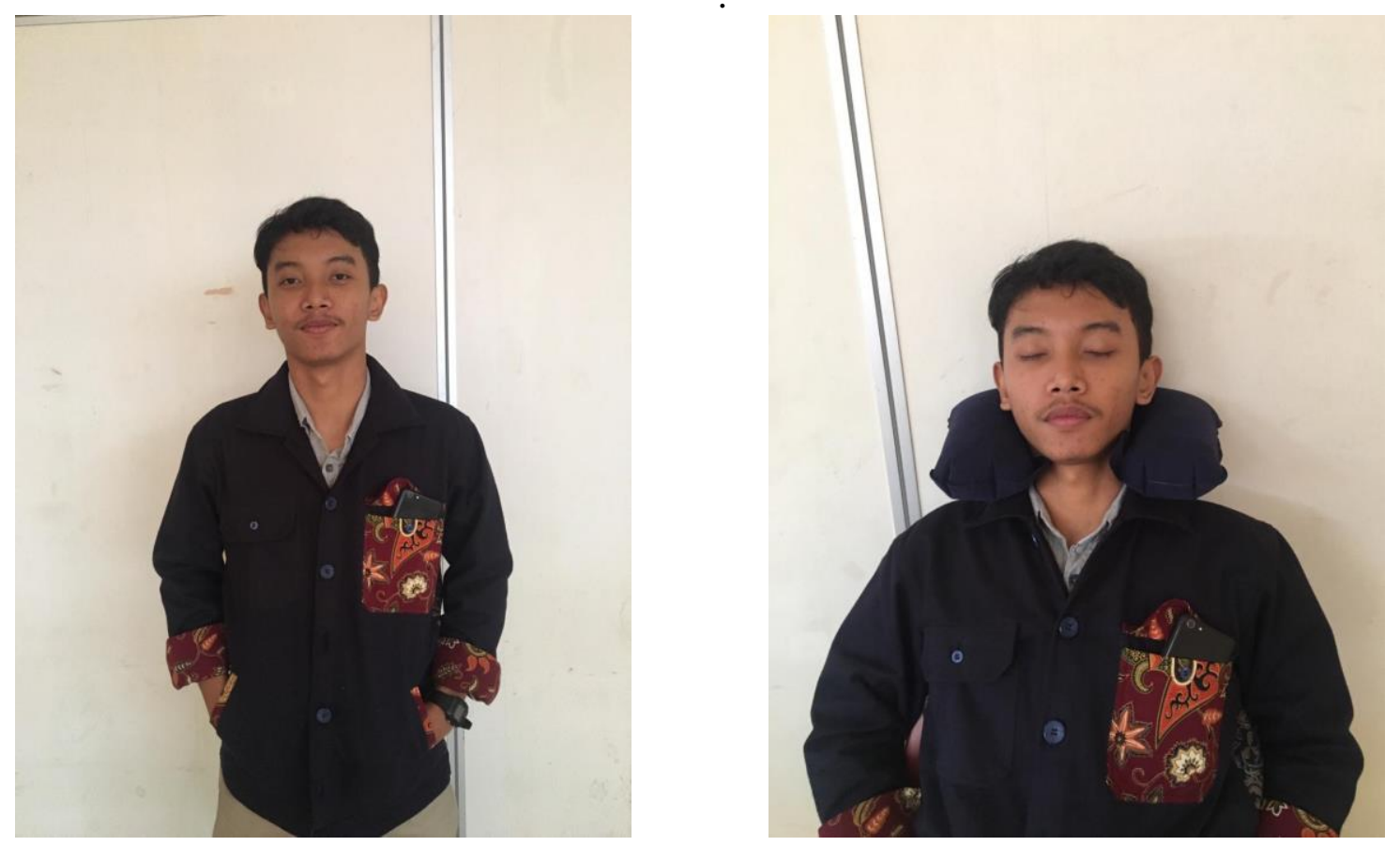


\section{Buletin Ekonomi}

\section{ANALISIS DAN PEMBAHASAN}

Hasil dari PKM-K "JATIKMAN" ini diharapkan dapat memberikan solusi terhadap peningkatan minat penggunaan batik pada masyarakat. Karena Daerah Istimewa Yogyakarta terkenal sebagai kota wisata banyak wisatawan yang datang ke Yogyakarta hal ini merupakan pangsa pasar yang besar mengingat setiap tahun wisatawan di Yogyakarta selalu meningkat. Terlebih lagi batik itu sebagai ciri khas jogja sehingga menambah nilai plus pada JATIKMAN.

Harga jual satuan "JATIK-MAN" sebesar Rp. 350.000. Penjualan mengalami kenaikkan dan penurunan. Kenaikkan terjadi saat waktu liburan karena banyak wisatawan yang datang ke Yogyakarta.

Tabel

Ketercapaian Target Luaran dapat dilihat sebagai berikut :

\begin{tabular}{|c|c|c|c|}
\hline \multirow[b]{2}{*}{ No. } & \multirow[b]{2}{*}{ Target } & \multicolumn{2}{|c|}{ Ketercapaian Target (100\%) } \\
\hline & & Sudah Tercapai & $\begin{array}{l}\text { Belum } \\
\text { Tercapai }\end{array}$ \\
\hline 1. & Survey Pasar & $100 \%$ & $0 \%$ \\
\hline 2. & $\begin{array}{l}\text { Pemenuhuan Alat dan } \\
\text { Bahan }\end{array}$ & $100 \%$ & $0 \%$ \\
\hline 3. & Tempat Produksi & $100 \%$ & $0 \%$ \\
\hline 4. & Pelaksanaan Produksi & $100 \%$ & $0 \%$ \\
\hline 5. & $\begin{array}{l}\text { Pemasaran } \\
\text { a. Sosial Media (Instagram, } \\
\text { Facebook, OA Line dan } \\
\text { Shopee) }\end{array}$ & $50 \%$ & $50 \%$ \\
\hline 6. & Laporan & $50 \%$ & $50 \%$ \\
\hline & Target Pencapaian & $\%$ & $\%$ \\
\hline
\end{tabular}

\section{KESIMPULAN DAN SARAN}

"Jatik Man" ini merupakan sebuah trobosan baru untuk mengangkat kearifan lokal yang fashionable, aman serta nyaman untuk digunakan dalam beraktivitas. Di Yogyakarta sendiri produsen "Jatik Man" masih belum ada sehingga pangsa pasar yang tersedia masih sangat luas untuk daerah Yogyakarta, apalagi Yogyakarta merupakan pusat industri batik sehingga bisa menjadi oleh-oleh khas Yogyakarta. Selain itu juga agar kaum muda minat dan bangga menggunakan batik sebagai kearifan lokal. "Jatik man" ini menggunakan bahan yang lembut serta nyaman digunakan dalam segala kondisi serta di lengkapi dengan bantal leher tiup yang fleksibel, ditambah dengan earphone yang menempel di telinga juga kabel yang dapat dicolokkan langsung di handphone yang sedang digunakan, oleh pengguna jaket itu sendiri.

\section{DAFTAR PUSTAKA}

Abror, Adam Ibrahim Al. 2018. Pengaruh Kualitas Produk Dan Harga Terhadap Keputusan Pembelian Jaket Pembelian. Vol 6 (1). 


\section{Buletin Ekonomi}

Dinas Pariwisata DIY. 2017. Statistik Kepariwisataan 2017. Yogyakarta: Dinas Pariwisata DIY.

http://www.bekraf.go.id/downloadable/pdf_file/170876-panduan-pendirian-usaha-batik.pdf di akses pada tanggal 24 juni 2019 pukul 13:00 WIB.

Takdir, Dedi, Mahmudin dan Sudirman Zain. 2015. Kewirausahaan. Yogyakarta: Wijana Mahadi Karya.

Yoebrilianti, Anggit. 2018. Pengaruh Promosi Penjualan Terhadap Minat Beli Produk Fashion Dengan Gaya Hidup Sebagai Variabel. Vol 8 (1). Manajemen 